\title{
Development of Guidelines for Skeletal Survey in Young Children With Fractures
}

AUTHORS: Joanne N. Wood, MD, MSHP, a,b,c Oludolapo Fakeye, MA, ${ }^{a}$ Chris Feudtner, MD, MPH, PhD, ${ }^{a, b, c}$ Valerie

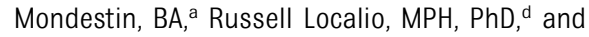
David M. Rubin, MD, MSCE

aDivision of General Pediatrics and PolicyLab, The Children's Hospital of Philadelphia, Philadelphia, Pennsylvania; ' ${ }^{\text {Leonard }}$ Davis Institute of Health Economics, and Departments of

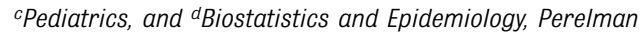
School of Medicine at the University of Pennsylvania, Philadelphia, Pennsylvania

\section{KEY WORDS}

child abuse, child maltreatment, fracture, skeletal survey, trauma

\section{ABBREVIATIONS}

AAP-American Academy of Pediatrics

MVC - motor vehicle crash

SES-socioeconomic status

SS-skeletal survey

UCLA-University of California Los Angeles

Drs Wood, Rubin, Feudtner, Fakeye, and Localio contributed to study concept and design; Dr Wood, Fakeye, and Mondestin contributed to acquisition of data; and all authors contributed to analysis and interpretation of data, drafting of the manuscript, critical revisions for important intellectual content, and approval of the manuscript. Dr Wood had full access to all of the data in the study and takes responsibility for the integrity of the data and the accuracy of the data analysis. All authors take public responsibility for the content presented in the manuscript.

\section{www.pediatrics.org/cgi/doi/10.1542/peds.2013-3242}

doi:10.1542/peds.2013-3242

Accepted for publication Apr 16, 2014

Address correspondence to Joanne N. Wood, MD, The Children's Hospital of Philadelphia, 3535 Market St, Room 1517, Philadelphia, PA 19104. E-mail: woodjo@email.chop.edu

PEDIATRICS (ISSN Numbers: Print, 0031-4005; Online, 1098-4275). Copyright (c) 2014 by the American Academy of Pediatrics

FINANCIAL DISCLOSURE: Dr Wood's institution has received payment for expert witness court testimony that Dr Wood has provided in cases of suspected child abuse; the other authors have indicated they have no financial relationships relevant to this article to disclose.

FUNDING: This study was funded by grant 1K23HD071967-01from the Eunice Kennedy Shriver National Institute of Child Health and Human Development. Funded by the National Institutes of Health (NIH).

POTENTIAL CONFLICT OF INTEREST: The authors have indicated they have no potential conflicts of interest to disclose.
(7) WHAT'S KNOWN ON THIS SUBJECT: Rates of performing skeletal survey (SS) for young children presenting with fractures and at risk for abuse vary substantially across providers, with disparities associated with patients' characteristics. Lack of consensus regarding indications for SS also contributes to this variation.

WHAT THIS STUDY ADDS: The results of this study provide a set of explicit consensus guidelines, based on the literature and on the knowledge of experts from several medical specialties, for identifying children with fractures who should undergo an initial SS.
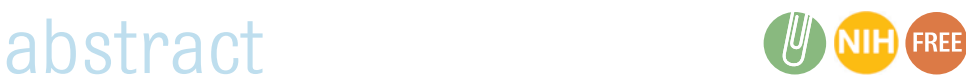

OBJECTIVE: To develop guidelines for performing initial skeletal survey (SS) in children $<24$ months old with fractures, based on available evidence and collective judgment of experts from diverse pediatric specialties.

METHODS: Following the Rand/UCLA Method, a multispecialty panel of 13 experts applied evidence from a literature review combined with their own expertise in rating the appropriateness of performing an SS for 525 clinical scenarios involving fractures in children $<24$ months old. After discussion on the initial ratings, panelists rerated SS appropriateness for 240 revised scenarios and deemed that SSs were appropriate in 191 scenarios. The panelists then assessed in which of those 191 scenarios SSs were not only appropriate, but also necessary.

RESULTS: Panelists agreed that SS is "appropriate" for 191 (80\%) of 240 scenarios rated and "necessary" for 175 (92\%) of the appropriate scenarios. Skeletal survey is necessary if a fracture is attributed to abuse, domestic violence, or being hit by a toy. With few exceptions, SS is necessary in children without a history of trauma. In children $<12$ months old, SS is necessary regardless of the fracture type or reported history, with rare exceptions. In children 12 to 23 months old, the necessity of obtaining SS is dependent on fracture type.

CONCLUSIONS: A multispecialty panel reached agreement on multiple clinical scenarios for which initial SS is indicated in young children with fractures, allowing for synthesis of clinical guidelines with the potential to decrease disparities in care and increase detection of abuse. Pediatrics 2014;134:45-53 
Each year, 8000 to 9000 children $<2$ years old are hospitalized in the United States with a fracture. ${ }^{1,2} \mathrm{~A}$ diagnosis of physical abuse is made in approximately $20 \%$ to $25 \%$ of fracture cases in children $<12$ months old and in $6 \%$ to $7 \%$ for children 12 to 23 months old, ${ }^{1-3}$ but the true proportion of cases attributable to abuse is higher, as medical providers frequently fail to recognize the abusive origin of injuries in children. ${ }^{4-6}$ Fractures are one of the most common injuries for which victims of abuse seek medical care, but fractures are also a common accidental injury. ${ }^{7-9}$ Distinguishing cases of abusive fractures from accidental fractures can be difficult. 9,10 Nevertheless, failure of providers to diagnose abuse can result in children suffering morbidity and mortality from additional undiagnosed injuries as well as on-going abuse.5,6,11-13 Thus, a thorough evaluation must be performed in young children with fractures that could be suspicious for abuse. $9,10,14$

Young victims of abuse frequently have occult fractures or fractures that are not suspected on history and physical examination but revealed on skeletal survey (SS), a series of $\sim 20$ radiographs. ${ }^{14-21}$ In addition to using SS to identify occult fractures in children presenting with injuries that are clearly the result of abuse, clinicians use SS in determining level of concern for abuse in young children presenting with injuries of unclear etiology. 15,20 Hence, recommendations of the American Academy of Pediatrics (AAP) emphasize performing SS in cases of suspected physical abuse in children $<2$ years old. ${ }^{14,15} \mathrm{SSs}$, however, expose children to radiation, and the AAP advises against $S S$ in cases in which occult injuries are unlikely.

Hospital-based variation in using SS for evaluation of possible abuse has been documented.22 Quality concerns are raised in studies highlighting missed opportunities to diagnose abuse.5,6,9,11-13,23 Research also has revealed disparities in the frequency of performing SS and diagnosing abuse in children with fractures based on race and socioeconomic status (SES) of families. ${ }^{24-27}$ The observed disparities raise concern for underevaluation and underdiagnosis of abuse in some groups (white, high SES), as well as overevaluation and overdiagnosis of abuse in other groups (racial minority, low SES).

Efforts to reduce disparities and improve quality of care provided to children with injuries suspicious of abuse have been hindered by the lack of clear criteria regarding when SS is necessary. The AAP recommends SS in cases of suspected abuse, but the term "suspected" is not defined and may be interpreted differently by clinicians. ${ }^{15,20}$ In a recently updated report, the AAP provided additional valuable guidance to clinicians on the many factors to consider when identifying child abuse as the cause of fractures. ${ }^{9}$ Concrete recommendations on which specific fracture scenarios should raise suspicion for abuse and prompt ordering of SS, however, are not available. The goal of this study was to develop guidelines for initial SS in young children presenting with fractures, with emphasis on including a diversity of provider perspectives. The explicit target for the guidelines was children $<2$ years old, because SS is less likely to reveal occult fractures in older children. ${ }^{15}$

\section{METHODS}

We applied the Rand/UCLA Appropriateness Method, which combines expert opinion and evidence, to identify clinical scenarios for which SS is appropriate, as well as scenarios for which SS is not only appropriate, but also necessary. ${ }^{28}$ The Rand method, a modified Delphi process that pro- vides expert panelists with the opportunity to discuss their judgments, has been shown to have high content, construct, and predictive validities for developing appropriateness criteria..29-31 Per Rand definitions, a procedure is appropriate for a scenario if the expected health benefit exceeds the expected negative consequences "by a sufficiently wide margin to make it worth doing, exclusive of cost." $28 \mathrm{~A}$ procedure is necessary if it has been deemed appropriate and meets the following additional criteria: (1) not offering the procedure would be improper, (2) there is a reasonable chance of the procedure benefiting the patient, and (3) the magnitude of the benefit is not small. ${ }^{28}$

Following Rand protocol, 3 preparatory steps were completed: (1) compiling a literature review on SS in children with fractures, (2) generating a list of clinical scenarios/vignettes that characterized children with fractures for whom SS might be considered, and (3) convening a panel of experts (Fig 1). Then, the following processes were completed sequentially: (1) panelists rated the appropriateness of SS for each clinical scenario (Round 1); (2) panelists reviewed the ratings and made revisions to scenarios during a moderated discussion; (3) panelists rerated the appropriateness of SS for the revised list of scenarios (Round 2); (4) scenarios were categorized as appropriate, uncertain, or inappropriate for SS based on Round 2 ratings; (5) panelists rated the necessity of SS for scenarios previously categorized as appropriate (Round 3); and (6) appropriate scenarios were further categorized as necessary or unnecessary for SS based on Round 3 ratings.

The Children's Hospital of Philadelphia's Institutional Review Board exempted this study as non-human subjects research. 


\begin{tabular}{|c|c|c|c|c|c|c|}
\hline $\begin{array}{l}\text { Preparatory } \\
\text { Steps }\end{array}$ & $\begin{array}{l}\text { Step1: } \\
\text { Round 1 } \\
\text { Ratings }\end{array}$ & $\begin{array}{l}\text { Step 2: } \\
\text { Moderated } \\
\text { Discussion }\end{array}$ & $\begin{array}{l}\text { Step 3: } \\
\text { Round 2 } \\
\text { Ratings }\end{array}$ & $\begin{array}{c}\text { Step 4: } \\
\text { Appropriateness } \\
\text { Categorization }\end{array}$ & $\begin{array}{l}\text { Step 5: } \\
\text { Round } 3 \\
\text { Ratings }\end{array}$ & $\begin{array}{c}\text { Step 6: } \\
\text { Necessity } \\
\text { Categorization }\end{array}$ \\
\hline $\begin{array}{l}\text { Review } \\
\text { literature }\end{array}$ & \multirow{3}{*}{$\begin{array}{c}\text { Panelists } \\
\text { independently } \\
\text { rate } \\
\text { appropriateness } \\
\begin{array}{c}\text { of SS for } \\
\text { each scenario }\end{array}\end{array}$} & \multirow{3}{*}{$\begin{array}{l}\text { Review of } \\
\text { rating results } \\
\text { and revision } \\
\text { of scenarios }\end{array}$} & \multirow{3}{*}{$\rightarrow \begin{array}{c}\text { Panelists } \\
\text { independently } \\
\text { rate } \\
\text { appropriateness } \\
\text { of SS for } \\
\text { each revised } \\
\text { scenario }\end{array}$} & \multirow{3}{*}{\begin{tabular}{|l|}
\multicolumn{1}{|c|}{ Scenarios } \\
categorized as: \\
1) Appropriate \\
2) Uncertain \\
3) Inappropriate \\
for SS
\end{tabular}} & \multirow{3}{*}{$\begin{array}{c}\text { Panelists } \\
\text { independently } \\
\text { rate necessity } \\
\text { of SS for } \\
\text { each scenario } \\
\text { categorized as } \\
\text { appropriate }\end{array}$} & \multirow{3}{*}{$\Rightarrow \begin{array}{c}\text { Appropriate } \\
\text { scenarios further } \\
\text { categorized as: } \\
\text { 1) Necessary } \\
\text { 2) Uncertain } \\
\text { 3) Not Necessary } \\
\text { for SS }\end{array}$} \\
\hline $\begin{array}{l}\text { Generate } \\
\text { scenarios }\end{array} \rightarrow$ & & & & & & \\
\hline $\begin{array}{c}\text { Select } \\
\text { expert panel }\end{array}$ & & & & & & \\
\hline
\end{tabular}

FIGURE 1

Procedure of the Rand/UCLA Appropriateness Method

\section{Literature Review}

Based on the literature review in PubMed/Medline of English language journals published between 1990 and 2011, and excluding surveys, reviews, editorials, and case studies, the authors synthesized the evidence on (1) efficacy, risks, utilization trends, and costs of SS in children with fractures; (2) probability of abuse in children with fractures; and (3) probability of occult fractures in children presenting with fractures. Titles and abstracts of identified studies were screened and nonrelevant studies were eliminated. Full manuscripts for the remaining studies were reviewed for eligibility. Using a standardized form, 3 of the authors (J.W., O.F., V.M.) extracted the following from 41 included studies: (1) study population characteristics, (2) inclusion and exclusion criteria, (3) methodology used to diagnose abuse, and (4) proportion of study population and subpopulations diagnosed as abused. The probability of abuse with $95 \%$ confidence intervals was calculated for children with specific fracture types. Finally, we calculated sensitivity, specificity, and positive and negative likelihood ratios of different clinical characteristics for abuse. See Supplemental Appendix 1 for the list of included studies.

\section{Expert Panel Assembly}

A panel of 13 experts representing a diverse set of clinical views $28,32,33$ was recruited from key pediatric specialties, including child abuse, emergency medicine, trauma, radiology, and orthopedics (Supplemental Appendix 2). Panelists were identified through the following mechanisms: (1) nominations, including self-nominations, from individuals with leadership roles in national professional organizations; (2) review of the literature to identify individuals publishing in the field; and (3) and solicitations of recommendations from colleagues. Panelists were purposively selected to ensure diversity with respect to practice location (Northeast, Midwest, West, and South), demographic characteristics, and practice experience (1-23 years).

\section{Appropriateness Criteria:}

\section{Development of Scenarios and}

\section{Round 1}

A Web-based questionnaire developed in Research Electronic Data Capture ${ }^{34}$ listed 525 clinical scenarios organized into 8 modules. Each scenario characterized a child with a fracture for whom SS might be considered. Module 1 explored the role of the following parameters on the decision to obtain SS in a child with a fracture: (1) delay in seeking care, (2) additional injuries on physical examination, and (3) reported history of injury resulting from domestic violence or abuse. The remaining 7 modules were organized by fracture group (femur, humerus, rib, tibia/fibula, radius/ulna, skull, and clavicle). The parameters for each sce- nario in these 7 fracture modules were as follows: child age, reported history of trauma, fracture type. Scenarios were pilot-tested for clarity and modified as needed.

Via e-mail, each panelist received an introduction to the study, an electronic link to the questionnaire, literature review results, and standard instructions on rating the appropriateness of performing initial SS on a Likert scale of 1 to 9 for each scenario, with $1=$ Extremely Inappropriate, 5 = Uncertain, and $9=$ Extremely Appropriate. Panelists were advised to use the evidence from the literature review and their own clinical judgment to rate the appropriateness of performing SS considering the average patient who presents for care with conditions specified in the scenario. We asked panelists to make the following assumptions unless otherwise specified: (1) patient is not a victim of a motor vehicle crash (MVC) or other independently witnessed accidental trauma, (2) there is no known history of underlying bone disease (eg, osteogenesis imperfecta, osteopenia of prematurity) in the child, (3) physical examination does not reveal any additional injuries suggestive of abuse (eg, whip marks, extensive bruising, frenulum tears), and (4) there is not a clear history of birth trauma explaining the fracture. In the first round, panelists rated the appropriateness of SS for each scenario without interaction with other panelists. 
Appropriateness Criteria Rating:

Moderated Conference Call,

\section{Rounds 2 and 3}

In preparation for Round 2, each panelist received an anonymized summary of the panel's ratings and their own individual ratings for each scenario from round 1. During a moderated telephone conference, panelists discussed the ratings, focusing on scenarios in which there was disagreement. If the wording of a scenario was ambiguous, panelists proposed and voted on modifications to clarify the description. Based on consensus reached during the conference, some fracture subtypes were altered. Some scenarios with similar ratings were also collapsed into a single scenario, reducing the original 525 scenarios to 240 . For example, the rib module initially included 100 scenarios, but panelists rated SS appropriate for all scenarios and agreed to collapse the entire rib module into a single scenario. After the conference, panelists independently rated the appropriateness of SS for each of the 240 revised scenarios. The median rating and dispersion of ratings for each scenario was calculated. Per Rand methodology, we classified scenarios for which ratings of $\leq 3$ panelists were outside each 3-point region containing the median as having agreement, and scenarios for which 4 or more panelists' ratings were in each extreme (1-3 and 7-9) as having disagreement. ${ }^{27}$ Scenarios with median ratings of 7-9 without disagreement were categorized as "appropriate" and those with median ratings of $1-3$ without disagreement as "inappropriate." Scenarios with median ratings of 4-6 or any median with disagreement were categorized as "uncertain."

In round 3, panelists independently rated the necessity of SS for scenarios that were classified as appropriate in round 2. Scenarios with median ratings of 7 to 9 without disagreement were categorized as "necessary" and those with median ratings of 1 to 3 without disagreement as "appropriate but not necessary." Median ratings of 4 to 6 or any median with disagreement were categorized as "appropriate but uncertain whether necessary."

Summary guidelines were synthesized from the categorizations of scenarios in rounds 2 and 3 by the study team.

\section{RESULTS}

Agreement was reached that SS was appropriate in $79.6 \%$ (191), uncertain in $19.6 \%$ (47), and inappropriate in $0.8 \%$ (2) of the 240 scenarios rated in round 2. In 40 of the 47 scenarios categorized as uncertain, panelists agreed that there was uncertainty about the appropriateness of SS, whereas there was disagreement in 7 scenarios. The greatest disagreement was observed in scenarios involving children 12 to 23 months old with nonmetaphyseal fractures from a reported fall. Of the 191 scenarios for which SS was deemed appropriate, $175(91.6 \%)$ were confirmed as necessary.

\section{General Fractures Scenarios}

Panelists determined that SS is necessary for children 0 to 23 months old with fractures from abuse or domestic violence and for children with additional injuries unrelated to the fracture (ie, bruises, burns, whip marks). Panelists agreed that a delay in seeking care of $>24$ hours is an indication for SS in children 0 to 11 months old regardless of the fracture type or symptomatology (Table 1). In children 12 to 23 months old with a delay in care of $>24$ hours, SS is necessary only if the fracture is associated with significant pain and/or physical findings.

\section{Long-Bone Fractures}

Panelists determined that SS is necessary in children 0 to 11 months old with long-bone fractures regardless of history, with 2 exceptions: a distal radius/ulna buckle fracture or toddler fracture in children 9 to 11 months old with a reported fall while cruising or walking (Table 2). In children 12 to 23 months old, the appropriateness and necessity of SS varied with fracture type and history. SS was deemed necessary in all cases of a classic metaphyseal lesion and for fractures attributed to being hit by a toy or other object. Skeletal survey was judged inappropriate in children 12 to 23 months old with a long-bone fracture in 2 scenarios:

(1) distal radius/ulna buckle fracture

TABLE 1 Appropriateness and Necessity of SS for Children $<24$ Months Old With a Delay in Presentation to Care

\begin{tabular}{lllcc}
\hline \multirow{2}{*}{$\begin{array}{c}\text { Time From } \\
\text { Injury, } \mathrm{h}\end{array}$} & Age, mo & Fracture Types & \multicolumn{3}{c}{ Symptomatology } \\
\cline { 3 - 5 } & & & No Obvious Injury or Distress & Obvious Injury With Distress \\
\hline \multirow{3}{*}{$24-72$} & $0-11$ & Long bone & $\mathrm{N}$ & $\mathrm{N}$ \\
& & Skull & $\mathrm{N}$ & $\mathrm{N}$ \\
& \multirow{2}{*}{$12-23$} & Long bone & $\mathrm{U}$ & $\mathrm{N}$ \\
& & Skull & $\mathrm{U}$ & $\mathrm{N}$ \\
& & & $\mathrm{N}$ & $\mathrm{N}$ \\
& & & $\mathrm{N}$ & $\mathrm{N}$ \\
& $0-11$ & Long bone & $\mathrm{N}$ & $\mathrm{N}$ \\
\hline
\end{tabular}

Summary of panelists' ratings on clinical scenarios related to delay in presentation of care, across fracture groups and stratified by age. A, SS appropriate but not necessary; N, SS appropriate and necessary; U, uncertain whether SS is appropriate or not. 
TABLE 2 Appropriateness and Necessity of SS for Children With Long-Bone Fracture

\begin{tabular}{|c|c|c|c|c|c|c|c|c|c|}
\hline \multirow[t]{2}{*}{ Fracture Group } & \multirow[t]{2}{*}{ Age, mo } & \multirow[t]{2}{*}{ Fracture Types } & \multicolumn{7}{|c|}{ Caregiver-Reported History of Trauma } \\
\hline & & & None & $\begin{array}{l}\text { Blunt } \\
\text { Impact }^{\mathrm{a}}\end{array}$ & $\begin{array}{l}\text { Fall While Cruising, } \\
\text { Walking, Running }\end{array}$ & $\begin{array}{l}\text { Short Fall } \\
(\leq 3 \mathrm{ft})\end{array}$ & $\begin{array}{l}\text { High Fall } \\
(>3 \mathrm{ft})\end{array}$ & $\begin{array}{c}\text { Fall From } \\
\text { Caregiver Arms }\end{array}$ & $\begin{array}{l}\text { Fall With Caregiver } \\
\text { Landing on Child }\end{array}$ \\
\hline \multirow{6}{*}{ Humerus } & \multirow[t]{3}{*}{$0-11$} & Any & $\mathrm{N}$ & $\mathrm{N}$ & $\mathrm{N}$ & $\mathrm{N}$ & $\mathrm{N}$ & $\mathrm{N}$ & $\mathrm{N}$ \\
\hline & & CML & $\mathrm{N}$ & $\mathrm{N}$ & $\mathrm{N}$ & $\mathrm{N}$ & $\mathrm{N}$ & $\mathrm{N}$ & $\mathrm{N}$ \\
\hline & & $\begin{array}{l}\text { Salter with epiphyseal } \\
\text { separation }^{\mathrm{c}}\end{array}$ & $\mathrm{N}$ & $\mathrm{N}$ & A & N & A & A & A \\
\hline & \multirow[t]{3}{*}{$12-23$} & $\begin{array}{l}\text { Salter without epiphyseal } \\
\text { separation }\end{array}$ & $\mathrm{N}$ & $\mathrm{N}$ & U & U & U & U & U \\
\hline & & Supracondylar & $\mathrm{N}$ & $\mathrm{N}$ & U & U & U & U & U \\
\hline & & Diaphyseal & $\mathrm{N}$ & $\mathrm{N}$ & U & U & U & U & U \\
\hline \multirow{4}{*}{ Femur } & \multirow[t]{2}{*}{$0-11$} & CML & $\mathrm{N}$ & $\mathrm{N}$ & $\mathrm{N}$ & $\mathrm{N}$ & $\mathrm{N}$ & N & $\mathrm{N}$ \\
\hline & & Diaphyseal & $\mathrm{N}$ & $\mathrm{N}$ & $\mathrm{N}$ & $\mathrm{N}$ & $\mathrm{N}$ & $\mathrm{N}$ & $\mathrm{N}$ \\
\hline & \multirow[t]{2}{*}{$12-23$} & $\mathrm{CML}$ & $\mathrm{N}$ & $\mathrm{N}$ & $\mathrm{N}$ & $\mathrm{N}$ & $\mathrm{N}$ & $\mathrm{N}$ & $\mathrm{N}$ \\
\hline & & Diaphyseal & $\mathrm{N}$ & U & U & $\mathrm{N}$ & $\mathrm{N}$ & U & U \\
\hline \multirow{8}{*}{ Radius/ulna } & \multirow[t]{4}{*}{$0-11$} & CML & $\mathrm{N}$ & $\mathrm{N}$ & $\mathrm{N}$ & $\mathrm{N}$ & $\mathrm{N}$ & - & - \\
\hline & & Proximal buckle & $\mathrm{N}$ & $\mathrm{N}$ & $\mathrm{N}$ & $\mathrm{N}$ & $\mathrm{N}$ & - & - \\
\hline & & Distal buckle & $\mathrm{N}$ & $\mathrm{N}$ & U & $\mathrm{N}$ & $\mathrm{N}$ & - & - \\
\hline & & All others & $\mathrm{N}$ & $\mathrm{N}$ & $\mathrm{N}$ & $\mathrm{N}$ & $\mathrm{N}$ & - & - \\
\hline & \multirow[t]{4}{*}{$12-23$} & CML & $\mathrm{N}$ & $\mathrm{N}$ & $\mathrm{N}$ & N & $\mathrm{N}$ & - & - \\
\hline & & Proximal buckle & $\mathrm{N}$ & $\mathrm{N}$ & U & U & U & - & - \\
\hline & & Distal buckle & A & $\mathrm{N}$ & I & U & U & - & - \\
\hline & & All others & $\mathrm{N}$ & $\mathrm{N}$ & U & U & U & - & - \\
\hline \multirow{8}{*}{ Tibia/fibula } & \multirow[t]{4}{*}{$0-11$} & CML & $\mathrm{N}$ & $\mathrm{N}$ & $\mathrm{N}$ & N & $\mathrm{N}$ & - & - \\
\hline & & Toddler (distal spiral) & $\mathrm{N}$ & $\mathrm{N}$ & U & $\mathrm{N}$ & $\mathrm{N}$ & - & - \\
\hline & & Buckle & $\mathrm{N}$ & $\mathrm{N}$ & $\mathrm{N}$ & N & $\mathrm{N}$ & - & - \\
\hline & & All others & $\mathrm{N}$ & $\mathrm{N}$ & $\mathrm{N}$ & $\mathrm{N}$ & $\mathrm{N}$ & - & - \\
\hline & \multirow{4}{*}{$12-23$} & CML & $\mathrm{N}$ & $\mathrm{N}$ & $\mathrm{N}$ & $\mathrm{N}$ & $\mathrm{N}$ & - & - \\
\hline & & Toddler (distal spiral) & U & $\mathrm{N}$ & 1 & U & U & - & - \\
\hline & & Buckle & A & $\mathrm{N}$ & U & U & U & - & - \\
\hline & & All others & $\mathrm{N}$ & $\mathrm{N}$ & $\mathrm{N}$ & A & U & - & - \\
\hline
\end{tabular}

Summary of panelists' ratings on clinical scenarios related to presentations of long-bone fracture types, stratified by age. A, SS appropriate but not necessary; CML, classic metaphyseal lesion; I, SS inappropriate; N, SS appropriate and necessary; U, uncertain whether SS is appropriate or not. —, indicates that a scenario for that particular combination of history and fracture type was not included in the list of scenarios rated by the panelists.

a Blunt impact was defined as being hit by a toy or other object, except for femur fracture it was defined as another person landing on child's leg.

b This scenario was limited to children $\geq 9$ mo who are able to cruise or ambulate. For radius/ulna fractures, the scenario specifies that child fell onto an outstretched hand.

c Includes Salter Type 1 fractures.

with history of a fall onto an outstretched hand, and (2) tibia/fibula toddler fracture with history of a fall while walking. These were the only scenarios for which SS was deemed inappropriate.

\section{Skull Fractures}

Panelists agreed that SS is appropriate for all skull fracture cases in children 0 to 11 months old (Table 3). The procedure was deemed necessary for skull fractures in this age group, with the exception of infants 7 to 11 months old with linear, unilateral skull fractures attributed to a reported fall from a high height or from a fall with the caregiver landing on the child. Skeletal survey was regarded necessary in all cases of complex or ping-pong skull fractures.

\section{Rib Fractures}

Panelists agreed that SS is necessary for children 0 to 23 months old with rib fractures regardless of child age, history of trauma, and fracture location or number.

\section{Clavicle Fractures}

Given the possibility of birth injury, SS was of uncertain appropriateness for infants $\leq 10$ days old with an acute clavicle fracture and no history of trauma (Table 4). SS was appropriate but not necessary for infants 11 to 21 days old with acute fractures and infants $<30$ days old with healing fractures. Outside of the neonatal period, SS was pronounced necessary in all children $<24$ months old with exception of children 12 to 23 months old with a history of a fall.

\section{DISCUSSION}

Drawing on a review of the literature and using the Rand/UCLA Appropriateness Method, a multispecialty expert 
TABLE 3 Appropriateness and Necessity of SS for Children With Skull Fracture

\begin{tabular}{|c|c|c|c|c|c|c|c|}
\hline \multirow{2}{*}{$\begin{array}{l}\text { Fracture } \\
\text { Group }\end{array}$} & \multirow[t]{2}{*}{ Age, mo } & \multirow[t]{2}{*}{ Fracture Type } & \multicolumn{5}{|c|}{ Caregiver-Reported History of Trauma } \\
\hline & & & None & $\begin{array}{l}\text { Short Fall } \\
(\leq 3 \mathrm{ft})\end{array}$ & $\begin{array}{l}\text { High Fall } \\
(>3 \mathrm{ft})\end{array}$ & $\begin{array}{c}\text { Fall From } \\
\text { Caregiver Arms }\end{array}$ & $\begin{array}{c}\text { Fall With Caregiver } \\
\text { Landing on Child }\end{array}$ \\
\hline \multirow{12}{*}{ Skull } & \multirow[t]{4}{*}{$0-6$} & Linear/unilateral & $\mathrm{N}$ & $\mathrm{N}$ & $\mathrm{N}$ & $\mathrm{N}$ & $\mathrm{N}$ \\
\hline & & Linear/bilateral & $\mathrm{N}$ & $\mathrm{N}$ & $\mathrm{N}$ & $\mathrm{N}$ & $\mathrm{N}$ \\
\hline & & Complex & $\mathrm{N}$ & $\mathrm{N}$ & $\mathrm{N}$ & $\mathrm{N}$ & $\mathrm{N}$ \\
\hline & & Ping-pong & $\mathrm{N}$ & $\mathrm{N}$ & $\mathrm{N}$ & $\mathrm{N}$ & $\mathrm{N}$ \\
\hline & \multirow[t]{4}{*}{$7-11$} & Linear/unilateral & $\mathrm{N}$ & $\mathrm{N}$ & $A$ & $\mathrm{~N}$ & $A$ \\
\hline & & Linear/bilateral & $\mathrm{N}$ & $\mathrm{N}$ & $\mathrm{N}$ & $\mathrm{N}$ & $\mathrm{N}$ \\
\hline & & Complex & $\mathrm{N}$ & $\mathrm{N}$ & $\mathrm{N}$ & $\mathrm{N}$ & $\mathrm{N}$ \\
\hline & & Ping-pong & $\mathrm{N}$ & $\mathrm{N}$ & $\mathrm{N}$ & $\mathrm{N}$ & $\mathrm{N}$ \\
\hline & \multirow[t]{4}{*}{$12-23$} & Linear/unilateral & $\mathrm{N}$ & $A$ & U & U & U \\
\hline & & Linear/bilateral & $\mathrm{N}$ & $A$ & U & U & U \\
\hline & & Complex & $\mathrm{N}$ & $\mathrm{N}$ & $\mathrm{N}$ & $\mathrm{N}$ & $\mathrm{N}$ \\
\hline & & Ping-pong & $\mathrm{N}$ & $\mathrm{N}$ & $\mathrm{N}$ & $\mathrm{N}$ & $\mathrm{N}$ \\
\hline
\end{tabular}

Summary of panelists' ratings on clinical scenarios related to presentations of skull fracture types, stratified by age. A, SS appropriate but not necessary; N, SS appropriate and necessary; U, uncertain whether SS is appropriate or not.

TABLE 4 Appropriateness and Necessity of SSs for Children With Clavicle Fracture

\begin{tabular}{cccccc}
\hline Fracture Group & Child Age & \multicolumn{3}{c}{ Reported History and Age of Fracture } \\
\cline { 3 - 5 } & & \multicolumn{2}{c}{ No History of Trauma } & Fall & Blunt Impact $^{\mathrm{a}}$ \\
\cline { 3 - 5 } & & Acute Fracture & Healing Fracture & Acute Fracture & Acute Fracture \\
\hline \multirow{2}{*}{ Clavicle } & $0-10 \mathrm{~d}$ & $\mathrm{U}$ & $\mathrm{A}$ & $\mathrm{N}$ & $\mathrm{N}$ \\
& $11-21 \mathrm{~d}$ & $\mathrm{~A}$ & $\mathrm{~A}$ & $\mathrm{~N}$ & $\mathrm{~N}$ \\
& $22-30 \mathrm{~d}$ & $\mathrm{~N}$ & $\mathrm{~A}$ & $\mathrm{~N}$ & $\mathrm{~N}$ \\
& $1-11 \mathrm{mo}$ & $\mathrm{N}$ & $\mathrm{N}$ & $\mathrm{N}$ & $\mathrm{N}$ \\
\hline
\end{tabular}

Summary of panelists' ratings on clinical scenarios related to presentations of clavicle fracture types, stratified by age in days. A, SS appropriate but not necessary; N, SS appropriate and necessary; U, uncertain whether SS is appropriate or not. a Blunt impact was defined as being hit by a toy or other object.

b Scenarios described children with healing fractures discovered incidentally during chest imaging performed for unrelated medical reasons.

panel agreed on 175 clinical scenarios for which initial SS is appropriate and necessary in children $<24$ months old with specific fractures, permitting synthesis of guidelines for performing $\mathrm{SS}$ in this age group (Fig 2). First, panelists agreed that $\mathrm{SS}$ should be performed in children whenever a fracture is attributed to abuse, domestic violence, or to being hit by a toy or similar object. Second, they agreed that SS should be obtained in children with rib fractures and in children without a history of trauma to explain their fracture, except in the ambulatory child $\geq 12$ months old with a toddler fracture or buckle fracture of the radius/ulna or tibia/fibula. Third, panelists universally endorsed SS for children $<12$ months old with fractures, with a few noted exceptions. For children $\geq 12$ months old, however, there was more disagreement on appropriateness of SS. Appropriateness of the procedure for this age group depends more on fracture type than for the $<12$-month age group. The panel rarely found SS inappropriate for this population, possibly to allow leeway for consideration of other factors that may increase suspicion for abuse, such as a history of previous abuse.

Given the significant risk of abuse among children $<12$ months old with fractures, it is not surprising that these guidelines, like the AAP recommendations, advocate for almost universal SS screening in this population. ${ }^{1,2}$ Current clinical practices, however, diverge from these guidelines. In a recent study, only threequarters of infants $<12$ months old admitted to pediatric hospitals with non-MVC-related femur fractures received SS. ${ }^{22}$ In another study, fewer than half of infants $<12$ months old with complex skull fractures received SS. ${ }^{25}$ Thus, these guidelines have the potential to alter current clinical practice.

The use of Rand methodology in this study is not without limitations. Results from this process could vary based on the selected panelists' specialties. ${ }^{28}$ Although we included experts from various specialties purposely to provide diverse views, the opinions of our experts might not reflect the array of views of colleagues in their fields. Additional factors that were not captured in scenarios rated, such as comprehensive history of trauma, previous history of abuse, and observed caregiver-child interactions, might influence actual appropriateness and necessity determinations of SS. Finally, although the expert panel benefited from a review of the literature to inform their ratings, the available evidence is limited, and the panelists were allowed to incorporate their own opinions in decision-making. Thus, there is some uncertainty about the effectiveness of these guidelines to accurately identify those children at the highest risk of having occult fractures from abuse.

Despite these limitations, the results from this study provide a set of explicit consensus guidelines for performing initial SS in children with fractures. Research has demonstrated that the implementation of SS guidelines for injured children could decrease disparities in care and potentially increase abuse detection. ${ }^{35}$ Missed opportunities to diagnose abuse lead 


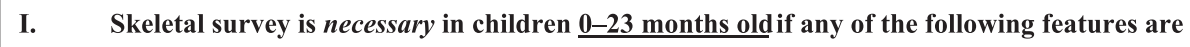
present:

- History of confessed abuse

- History of injury occurring during domestic violence

- History of impact from toy or other object causing fracture

- Delay in seeking care $>24$ hours in a child with obvious signs of distress

- Additional injuries on physical exam unrelated to fracture (ie, bruises, burns, whip marks)

- No history of trauma to explain fracture

- Except for the following fracture types in an ambulatory child $>12$ months old:

- Distal buckle fracture of the radius/ulna

- Distal spiral or buckle fracture of the tibia/fibula

II. Skeletal survey is necessary in ALL children 0-11 months old with ANY type of fracture except in the following cases if there are no additional concerns:

- Distal radial/ulna buckle fracture or toddler fracture of the tibia/fibula in a cruising child $\geq 9$ months old with a history of a fall.

- Linear, unilateral skull fracture in a child $>6$ months with a history of a significant fall (ie, height $>3 \mathrm{ft}$ or fall with caregiver landing on child.

- Clavicle fracture likely attributable to birth (acute fracture in infant $<22$ days old or healing fracture in infant $<30$ days old).

III. Skeletal survey is necessary in children 12-23 months old with any of the following types of

fractures:

- Rib fracture

- Classic metaphyseal lesion

- Complex or ping-pong skull fracture

- Humeral fracture with epiphyseal separation attributed to a short ( $\leq 3$ feet) fall

- Femur diaphyseal fracture attributed to a fall from any height

IV. Skeletal survey may be appropriate and should be considered in other cases

V. Skeletal survey should not be routinely performed in the following cases in the absence of other findings that raise concern for abuse:

- Distal spiral fracture of the tibia/fibula in a child 12-23 months old with a history of fall while walking/running

- Distal radial/ulna buckle fracture in an ambulatory child 12-23 months old with a history of a fall onto an outstretched hand

FIGURE 2

Summary of Key Skeletal Survey Guidelines. The guidelines synthesize the panelists' responses from Tables 1, 2, 3, and 4. They apply to children who do not have a verifiable mechanism of accidental trauma (ie, MVC or fall in public place), do not have underlying bone fragility, such as osteogenesis imperfecta, and who do not have a clear history of birth trauma that accounts for the injury.

not only to additional injuries directly related to the abuse, but also could contribute to chronic medical conditions and overall mortality.36-39 Thus, guidelines that improve early detection and diagnosis of abuse may affect not only abuse-related injuries, but also a wide range of adverse health outcomes. The guidelines developed in this study are not part of and are not intended to conflict with the recommendation of the AAP Section on Child Abuse to perform SS in cases of suspected physical abuse in children $<24$ months old. ${ }^{14}$ Instead, they are purposed to provide additional guidance to clinicians on specific scenarios for which it is appropriate to suspect abuse and perform SS. The guidelines developed in this study also could be applied retrospectively as performance measurement tools: the appropriateness criteria could be used to measure SS overuse, whereas the necessity criteria could be used to assess SS underuse. As the development of these guidelines relied on expert opinion and the limited evidence available, future studies evaluating the predictive validity of the guidelines to identify children with positive screens for occult fractures are warranted.

\section{CONCLUSIONS}

Applying the Rand/UCLA Appropriateness Method, a multispecialty panel reached agreement on clinical scenarios for which initial SS is necessary in young children with fractures, permitting synthesis of guidelines for performing initial SS in this population. Postimplementation evaluation of these guidelines is needed to determine whether they achieve the goals of (1) decreasing variation and disparities in care, (2) increasing detection of cases of abuse, and (3) decreasing use of SS in children with low risk for occult fractures.

\section{ACKNOWLEDGMENTS}

We thank the panelists for the time, effort and expertise they dedicated to this project. See Supplemental Appendix 2 for a profile of the panelists. 


\section{REFERENCES}

1. Leventhal JM, Martin KD, Asnes AG. Incidence of fractures attributable to abuse in young hospitalized children: results from analysis of a United States database. Pediatrics. 2008;122(3):599-604

2. Leventhal JM, Martin KD, Asnes AG. Fractures and traumatic brain injuries: abuse versus accidents in a US database of hospitalized children. Pediatrics. 2010;126(1). Available at: www.pediatrics.org/cgi/content/full/126/1/e104

3. Skellern CY, Wood D0, Murphy A, Crawford $M$. Non-accidental fractures in infants: risk of further abuse. J Paediatr Child Health. 2000;36(6):590-592

4. Dalton HJ, Slovis T, Helfer RE, Comstock J, Scheurer S, Riolo S. Undiagnosed abuse in children younger than 3 years with femoral fracture. Am J Dis Child. 1990;144(8):875878

5. Ravichandiran N, Schuh S, Bejuk M, et al Delayed identification of pediatric abuserelated fractures. Pediatrics. 2010;125(1): 60-66

6. Oral R, Blum KL, Johnson C. Fractures in young children: are physicians in the emergency department and orthopedic clinics adequately screening for possible abuse? Pediatr Emerg Care. 2003;19(3): 148-153

7. Banaszkiewicz PA, Scotland TR, Myerscough EJ. Fractures in children younger than age 1 year: importance of collaboration with child protection services. J Pediatr Orthop 2002;22(6):740-744

8. Leventhal JM, Larson IA, Abdoo D, et al. Are abusive fractures in young children becoming less common? Changes over 24 years. Child Abuse Negl. 2007;31(3):311-322

9. Flaherty EG, Perez-Rossello JM, Levine MA, Hennrikus WL; American Academy of Pediatrics Committee on Child Abuse and $\mathrm{Ne}$ glect; Section on Radiology, American Academy of Pediatrics; Section on Endocrinology, American Academy of Pediatrics; Section on Orthopaedics, American Academy of Pediatrics; Society for Pediatric Radiology. Evaluating children with fractures for child physical abuse. Pediatrics. 2014;133(2). Available at: www.pediatrics. org/cgi/content/full/133/2/e477

10. Leventhal JM, Thomas SA, Rosenfield NS, Markowitz RI. Fractures in young children. Distinguishing child abuse from unintentional injuries. Am J Dis Child. 1993; 147(1):87-92

11. Jenny C, Hymel KP, Ritzen A, Reinert SE, Hay TC. Analysis of missed cases of abusive head trauma. JAMA. 1999;281 (7):621-626
12. King WK, Kiesel EL, Simon HK. Child abuse fatalities: are we missing opportunities for intervention? Pediatr Emerg Care. 2006;22 (4):211-214

13. Thackeray JD. Frena tears and abusive head injury: a cautionary tale. Pediatr Emerg Care. 2007;23(10):735-737

14. Kellogg ND; American Academy of Pediatrics Committee on Child Abuse and Neglect. Evaluation of suspected child physical abuse. Pediatrics. 2007;119(6):1232-1241

15. Section on Radiology; American Academy of Pediatrics. Diagnostic imaging of child abuse. Pediatrics. 2009;123(5):1430-1435

16. ACR-SPR Practice Guideline for Skeletal Surveys in Children. 2011. Available at: www. acr.org/ /media/ACR/Documents/PGTS/ guidelines/Skeletal_Surveys.pdf. Accessed May 7, 2014

17. Degraw M, Hicks RA, Lindberg D; Using Liver Transaminases to Recognize Abuse (ULTRA) Study Investigators. Incidence of fractures among children with burns with concern regarding abuse. Pediatrics. 2010; 125(2). Available at: www.pediatrics.org/ cgi/content/full/125/2/e295

18. Belfer RA, Klein BL, Orr L. Use of the skeletal survey in the evaluation of child maltreatment. Am J Emerg Med. 2001;19(2):122-124

19. Hicks RA, Stolfi A. Skeletal surveys in children with burns caused by child abuse. Pediatr Emerg Care. 2007;23(5):308-313

20. Duffy S0, Squires J, Fromkin JB, Berger RP. Use of skeletal surveys to evaluate for physical abuse: analysis of 703 consecutive skeletal surveys. Pediatrics. 2011;127(1). Available at: www.pediatrics.org/cgi/content/full/127/1/e47

21. Mandelstam SA, Cook D, Fitzgerald $M$, Ditchfield MR. Complementary use of radiological skeletal survey and bone scintigraphy in detection of bony injuries in suspected child abuse. Arch Dis Child. 2003; 88(5):387-390, discussion 387-390

22. Wood JN, Feudtner C, Medina SP, Luan X, Localio $R$, Rubin DM. Variation in occult injury screening for children with suspected abuse in selected US children's hospitals. Pediatrics. 2012;130(5):853-860

23. Trokel M, Waddimba A, Griffith J, Sege R. Variation in the diagnosis of child abuse in severely injured infants. Pediatrics. 2006; 117(3):722-728

24. Lane WG, Rubin DM, Monteith R, Christian $\mathrm{CW}$. Racial differences in the evaluation of pediatric fractures for physical abuse. JAMA. 2002;288(13):1603-1609

25. Wood JN, Christian CW, Adams CM, Rubin DM. Skeletal surveys in infants with iso- lated skull fractures. Pediatrics. 2009;123 (2). Available at: www.pediatrics.org/cgi/ content/full/123/2/e247

26. Lane WG, Dubowitz $\mathrm{H}$. What factors affect the identification and reporting of child abuse-related fractures? Clin Orthop Relat Res. 2007;461(461):219-225

27. Laskey AL, Stump TE, Perkins SM, Zimet GD, Sherman SJ, Downs SM. Influence of race and socioeconomic status on the diagnosis of child abuse: a randomized study. $J$ Pediatr. 2012;160(6):1003-1008.e1

28. Fitch K, Bernstein SJ, Aguilar MS, et al. The RAND/UCLA Appropriateness Method User's Manual. Santa Monica, CA: RAND Corporation; 2001. Available at: www.rand.org/pubs/ monograph_reports/MR1269.html.Accessed May 7, 2014

29. Yermilov I, McGory ML, Shekelle PW, Ko CY, Maggard MA. Appropriateness criteria for bariatric surgery: beyond the NIH guidelines. Obesity (Silver Spring). 2009;17(8): 1521-1527

30. Shekelle PG, Schriger DL. Evaluating the use of the appropriateness method in the Agency for Health Care Policy and Research Clinical Practice Guideline Development process. Health Serv Res. 1996;31(4):453-468

31. Shekelle PG, Chassin MR, Park RE. Assessing the predictive validity of the RAND/UCLA appropriateness method criteria for performing carotid endarterectomy. Int $J$ Technol Assess Health Care. 1998;14(4): 707-727

32. Leape LL, Park RE, Kahan JP, Brook RH. Group judgments of appropriateness: the effect of panel composition. Qual Assur Health Care. 1992;4(2):151-159

33. Coulter I, Adams A, Shekelle P. Impact of varying panel membership on ratings of appropriateness in consensus panels: a comparison of a multi- and single disciplinary panel. Health Serv Res. 1995;30(4): 577-591

34. Harris PA, Taylor R, Thielke R, Payne J, Gonzalez N, Conde JG. Research electronic data capture (REDCap) — a metadata-driven methodology and workflow process for providing translational research informatics support. J Biomed Inform. 2009;42(2): 377-381

35. Rangel EL, Cook BS, Bennett BL, Shebesta K, Ying $\mathrm{J}$, Falcone RA. Eliminating disparity in evaluation for abuse in infants with head injury: use of a screening guideline. J Pediatr Surg. 2009;44(6):1229-1234; discussion 1234-1225

36. Felitti VJ, Anda RF, Nordenberg D, et al. Relationship of childhood abuse and 
household dysfunction to many of the leading causes of death in adults. The Adverse Childhood Experiences (ACE) Study. Am J Prev Med. 1998;14(4):245-258

37. Chartier MJ, Walker JR, Naimark B. Separate and cumulative effects of adverse childhood experiences in predicting adult health and health care utilization. Child Abuse Negl. 2010;34(6):454-464

38. Middlebrooks JS, Audage NC. The Effects of Childhood Stress on Health Across the Lifespan. Atlanta, GA: Centers for Disease
Control and Prevention, National Center for Injury Prevention and Control; 2008

39. Flaherty EG, Thompson R, Litrownik AJ, et al. Effect of early childhood adversity on child health. Arch Pediatr Adolesc Med. 2006;160(12):1232-1238

PROTEIN AND LIFE EXPECTANCY: For years, many weight loss advocates have suggested that a high protein diet is the best way to lose weight. Indeed, several studies have shown that high-protein, low-carbohydrate diets are effective for weight loss and can help normalize blood-glucose levels. The long term outcome of high protein diets, however, has not been known. As reported in The Wall Street Journal (Life \& Culture: March 12, 2014), two recent studies, one in mice and the other in humans, suggest that high protein diets may decrease life expectancy. In the animal study, more than 850 mice were fed one of several different diets each with a specific ratio of protein to carbohydrates. Mice that consumed higher ratios of protein to carbohydrates were leaner than those who consumed diets with a lower protein to carbohydrate ratio. However, the high protein diets came at a price: decreased life expectancy. Mice with diets consisting of lower amounts of protein had a 30\% increased life span than those mice who consumed higher amounts of protein. In the human study, more than 6300 adults were followed for 18 years after completing a 24 hour food diary. Subjects were placed into one of three protein consumption groups based on the percentage of calories from protein: high (>20\%); moderate (10-19\%); and low (<10\%). Compared to those with low protein diets, adults aged 50-65 with moderate and high protein diets had up to a $74 \%$ increase in their relative risk of all-cause mortality. Oddly, those over 65 seemed to benefit from the high protein diet.

How to interpret these data is a bit problematic. For one, humans are not mice. Moreover, in humans, dietary habits can change over time. The timing of meals and the age of diner may influence results. For example, many Americans eat the majority of protein in the evening at dinner and not all the protein consumed will be absorbed. The elderly may benefit from a high protein diet because protein absorption decreases with age. Given the confusing data, the old adage seems appropriate: everything in moderation. 